\title{
Silagem de grão úmido de milho na alimentação de coelhos em crescimento
}

\author{
High moisture corn silage in diets for growing rabbits
}

\section{Claudio Scapinello ${ }^{\mathrm{I}}$ Clóves Cabreira Jobim ${ }^{\mathrm{II}}$ Haroldo Garcia de Faria'II Antônio Claudio Furlan ${ }^{\mathrm{II}}$ Márcia Aparecida Andreazzi ${ }^{\mathrm{IV}}$ Andréia Fróes Galuci Oliveira ${ }^{\mathrm{II}}$ Marciana Retore $^{\mathrm{II}}$}

RESUMO

Dois experimentos foram realizados para determinar o valor nutritivo da silagem de grãos úmidos de milho (SGUM) e avaliar os efeitos da substituição gradativa do milho seco das rações pela SGUM sobre o desempenho e características quantitativas de carcaça de coelhos, no período de 36 a 70 dias de idade. No ensaio de digestibilidade, foram utilizados 22 coelhos da raça Nova Zelândia Branco, com 50 dias de idade, alojados individualmente em gaiolas de metabolismo, em delineamento inteiramente ao acaso, com dois tratamentos e 11 repetições. Os valores da matéria seca digestivel, proteína bruta digestível, energia bruta digestível, fibra em detergente neutro digestível, fibra em detergente ácido digestível e amido digestível da SGUM foram, respectivamente, 94,42\%; 7,94\%; 3973kcal kg-1, 6,74\%; 2,61\% e 68,73\%. No experimento de desempenho, foram utilizados 110 coelhos, distribuídos em um delineamento inteiramente casualizado, com cinco tratamentos, 11 repetições e dois animais por unidade experimental. Os tratamentos consistiram de uma dieta referência e outras quatro com 25, 50, 75 e 100\% de substituição do milho pela SGUM, com base na matéria seca do milho incluído na dieta referência. Não foram observadas diferenças entre os tratamentos no desempenho, tanto no período de 36 a 50 dias como no período total do experimento, de 36 a 70 dias de idade. Nenhuma diferença foi observada no peso $e$ rendimento de carcaça entre os tratamentos. Diante dos resultados, a SGUM substitui eficientemente o milho seco em dietas para coelhos.

Palavras-chave: conversão alimentar, desempenho, digestibilidade, rendimento de carcaça.

\begin{abstract}
Digestibility and performance experiments were carried out to evaluate the nutrients digestibility coefficients of high moisture corn silage (HMCS) and the gradative replacing $(0,25,50,75$ and 100\%) of dry grain corn by HMCS on performance and carcass yield of growing rabbits from 36 to 70 days old. In the digestibility experiment 22 rabbits were used allocated on a completely randomized design, with two treatments and 11 replicates. The values of digestible dry matter, digestible crude protein, digestible crude energy, digestible neutral fiber detergent, digestible acid fiber detergent and digestible starch were, respectively, $94.42 \% ; 7.94 \% ; 3973 \mathrm{kcal}$ $\mathrm{kg}^{-1} ; 6.74 \% ; 2.61 \%$ and $68.73 \%$. In the performance experiment, 110 rabbits were allocated on a completely randomized design, with five treatments, 11 replications and two rabbits per experimental unit. The HMCS replaced the dry grain corn in levels of 0, 25, 50, 75 and 100\%, on dry matter basis. No differences were observed on performance in the period from 36 to 50 and the period from 36 to 70 days old. No difference was observed also on weight and carcass yield. The results showed that the HMCS replaces efficiently the dry grain corn in rabbit diets.
\end{abstract}

Key words: carcass yield, digestibility, feed conversion, performance

\section{INTRODUÇÃO}

O milho seco é a principal fonte energética empregada na alimentação de animais não-ruminantes.

'Programa de Pós-graduação em Zootecnia, Centro de Ciências Agrárias (CCA), Universidade Estadual de Maringá (UEM), Avenida Colombo, 5790, Zona 7, 87020-900, Maringá, PR, Brasil. E-mail: cscapinello@uem.br. Autor para correspondência.

"Departamento de Pós-graduação em Zootecnia, UEM, Maringá, PR, Brasil.

II'Biotério Central, UEM, Maringá, PR, Brasil.

${ }^{\mathrm{IV}}$ Centro Universitário de Maringá (CESUMAR), Maringá, PR, Brasil 
No entanto, o emprego do milho na forma de silagem de grãos úmidos em rações para animais tem sido uma alternativa para a utilização na propriedade. A silagem apresenta várias vantagens em relação ao milho seco, entre elas, a economia de transporte, menor custo de armazenamento, antecipação do período de colheita e menores perdas por ataques de roedores e insetos (JOBIM et al., 2001). A silagem de grãos úmidos pode ser definida como o produto da conservação, em meio anaeróbico, de grãos de cereais, logo após a maturação fisiológica, com teor de umidade entre 25 e $30 \%$. A maturação fisiológica caracteriza-se pelo momento em que cessa a translocação de nutrientes da planta para os grãos, momento em que apresenta teores máximos de amido, proteína e óleo (BIAGI et al., 1996).

De acordo com LIMA et al. (1998), a fermentação anaeróbica propicia um produto com maior disponibilidade de energia. Isso está relacionado ao processo fermentativo que se desenvolve no interior do silo, o qual favorece a gelatinização parcial do amido. Adicionalmente, o melhor valor nutricional de dietas contendo silagem deve-se às alterações físicas e químicas que ocorrem no endosperma e na superfície dos grânulos de amido durante o processo fermentativo, podendo aumentar a susceptibilidade ao ataque enzimático durante a digestão (LOPES et al., 2002).

Dependendo da fonte do amido e da idade do coelho, a excreção de amido pode representar 10 a $12 \%$ do ingerido (BLAS \& GIDENNE, 1998). Assim, a ensilagem, por aumentar a digestibilidade desse nutriente, aumenta sua utilização pelo animal, minimizando as perdas. Além disso, a acidez da silagem favorece a saúde do trato gastrintestinal dos coelhos, reduzindo os riscos de problemas digestivos, frequentes do desmame até os 50 dias de idade dos animais.

Diante dessa alternativa de uso de grão de milho na alimentação animal, os objetivos deste trabalho foram avaliar a digestibilidade dos nutrientes da silagem de grão úmido de milho (SGUM) e sua utilização em dietas para coelhos em crescimento em substituição ao milho seco.

\section{MATERIAL E MÉTODOS}

Foram conduzidos um ensaio de digestibilidade e um experimento de desempenho, utilizando as instalações do setor de cunicultura, na Fazenda Experimental de Iguatemi, da Universidade Estadual de Maringá para determinar o valor nutritivo da SGUM e avaliar a sua utilização em dietas de coelhos em crescimento.
No ensaio de digestibilidade, foram utilizados 22 coelhos da raça Nova Zelândia Branco, com 50 dias de idade, alojados individualmente em gaiolas de metabolismo. Os animais foram distribuídos em delineamento inteiramente ao acaso, com dois tratamentos, consistindo de uma dieta referência (Tabela 1) e uma dieta teste, em que a SGUM substituiu, na base da matéria seca, $25 \%$ da dieta referência e 11 repetições. O experimento teve duração de 14 dias, sendo 10 dias para adaptação às rações experimentais e às gaiolas e quatro dias para coleta de fezes, utilizando-se a metodologia padronizada para ensaios de digestibilidade in vivo, descrita por PEREZ et al. (1995).

Para o preparo da SGUM, a colheita do milho foi efetuada no período do inverno, utilizando-se o milho "safrinha", quando este se apresentava em fase de maturação fisiológica. $\mathrm{O}$ milho foi colhido com colheitadeira de grãos, em seguida processado em triturador de faca com peneira de $13 \mathrm{~mm}$ e após foi armazenado, com boa compactação, em silos experimentais. Foram utilizados como silos experimentais, tambores de polietileno com tampa dupla (vedar e de rosca), com capacidade de $0,2 \mathrm{~m}^{3}$ de silagem (aproximadamente $200 \mathrm{~kg}$ ). Após 30 dias de armazenagem, os silos foram abertos para utilização da silagem nas rações experimentais e amostras foram retiradas para determinação de $\mathrm{pH}$, utilizando-se o procedimento descrito por PHILLIP \& FELLNER (1992). As análises laboratoriais da matéria seca (MS), proteína bruta (PB), fibra em detergente neutro (FDN), fibra em detergente ácido (FDA) e energia bruta (EB) foram realizadas de acordo com SILVA (1990), e do amido pelo método de POORE et al. (1989) adaptado por PEREIRA \& ROSSI (1995).

As rações foram fornecidas à vontade durante todo o ensaio. As fezes de cada animal foram coletadas, em sua totalidade, no período da manhã, acondicionadas em sacos plásticos e armazenadas em freezer a $-10^{\circ} \mathrm{C}$. Posteriormente, ao final do período experimental, as fezes de cada animal foram pesadas, homogeneizadas e colocadas em estufas de ventilação forçada a $55^{\circ} \mathrm{C}$, durante 72 horas. Em seguida, foram moídas e acondicionadas em vidros, devidamente identificados, para análises laboratoriais.

Para os cálculos dos coeficientes de digestibilidade, foi utilizada a metodologia de MATTERSON et al. (1965). Para obtenção dos valores de nutrientes digestíveis, aplicaram-se os valores do coeficiente de digestibilidade sobre a composição química da SGUM.

O modelo matemático utilizado foi o seguinte:

$\mathrm{Y}_{\mathrm{ij}}=\mathrm{m}+\mathrm{D}_{\mathrm{i}}+\mathrm{e}_{\mathrm{ij}}$ em que:

$\mathrm{Y}_{\mathrm{ij}}=$ valor observado das variáveis estudadas, relativo a cada indivíduo $j$, recebendo a dieta $i$; 
Tabela 1 - Composição percentual e química das dietas experimentais.

\begin{tabular}{|c|c|c|c|c|c|}
\hline Ingredientes & Referência & 25 & 50 & 75 & 100 \\
\hline Milho & 27,25 & 20,44 & 13,63 & 6,81 & - \\
\hline SGUM $^{*}$ & - & 6,81 & 13,63 & 20,44 & 27,25 \\
\hline Farelo de soja & 10,15 & 10,15 & 10,15 & 10,15 & 10,15 \\
\hline Farelo de trigo & 19,80 & 19,80 & 19,80 & 19,80 & 19,80 \\
\hline Feno de alfafa & 25,00 & 25,00 & 25,00 & 25,00 & 25,00 \\
\hline Feno de aveia & 14,77 & 14,77 & 14,77 & 14,77 & 14,77 \\
\hline Sal comum & 0,40 & 0,40 & 0,40 & 0,40 & 0,40 \\
\hline Fosfato bicálcico & 0,33 & 0,33 & 0,33 & 0,33 & 0,33 \\
\hline Calcário & 0,62 & 0,62 & 0,62 & 0,62 & 0,62 \\
\hline L-Lisina HCL & 0,08 & 0,08 & 0,08 & 0,08 & 0,08 \\
\hline DL-Metionina & 0,10 & 0,10 & 0,10 & 0,10 & 0,10 \\
\hline Mistura Vit+Min ${ }^{1}$ & 0,50 & 0,50 & 0,50 & 0,50 & 0,50 \\
\hline Óleo de soja & 1,00 & 1,00 & 1,00 & 1,00 & 1,00 \\
\hline Nutrientes & \multicolumn{5}{|c|}{----1 } \\
\hline Proteína Bruta & 16,50 & 16,38 & 16,26 & 16,14 & 16,03 \\
\hline FDN & 27,40 & 27,40 & 27,40 & 27,40 & 27,40 \\
\hline FDA & 16,00 & 16,00 & 16,00 & 16,00 & 16,00 \\
\hline Cálcio & 1,00 & 1,00 & 1,00 & 1,00 & 1,00 \\
\hline Fósforo & 0,50 & 0,50 & 0,50 & 0,50 & 0,50 \\
\hline Energia digestível $\left(\mathrm{kcal} \mathrm{kg}^{-1}\right)$ & 2.570 & 2.570 & 2.570 & 2.570 & 2.570 \\
\hline
\end{tabular}

* Substituição com base na matéria seca do milho; ${ }^{1}$ Nuvital, composição por kg do produto: Vit A, 600.000UI; Vit D, 100.000UI; Vit E, $8.000 \mathrm{mg}$; Vit K3, 200mg; Vit B1, 400mg; Vit B2, 600mg; Vit B6, 200mg; Vit B12, 2.000mcg; Ac. Pantotênico, 2.000mg; Colina, 70.000mg; Ferro, 8.000mg; Cobre, 1.200mg; Cobalto, 200mg; Manganês, 8.600mg; Zinco, 12.000mg; Iodo, 64mg; Selênio, 16mg; Metionina, $120.000 \mathrm{mg}$; Antioxidante, $20.000 \mathrm{mg}$.

$\mathrm{m}=$ constante geral;

$\mathrm{D}_{\mathrm{i}}=$ efeito da dieta i sendo $i=1$ e $2\left(i_{1}=\right.$ dieta referência;

$i_{2}=$ dieta teste);

$\mathrm{e}_{\mathrm{ij}}=$ erro aleatório associado a cada observação.

Para o ensaio de desempenho foram utilizados 110 coelhos da raça Nova Zelândia Branco, 55 machos e 55 fêmeas, de 36 a 70 dias de idade, distribuídos em um delineamento em blocos ao acaso, com cinco tratamentos, 11 repetições e dois animais por unidade experimental. Os tratamentos consistiram de cinco dietas isoenergéticas, isocálcicas, isofosfóricas e isoaminoacídicas para lisina e metionina + cistina, em que o milho seco foi substituído em 0,25 , 50,75 e $100 \%$ pela SGUM, com base na matéria seca, atendendo às exigências nutricionais do AEC (1987) para coelhos em crescimento (Tabela 1).

Os animais desmamados foram alojados em gaiolas de arame galvanizado providas de bebedouro automático e comedouro semi-automático de chapa galvanizada, localizadas em galpão de alvenaria, com cobertura de telha francesa, pé-direito de $3 \mathrm{~m}$, piso em alvenaria, paredes laterais de $50 \mathrm{~cm}$ em alvenaria e o restante em tela e cortina de plástico para controle de ventos.
As dietas experimentais foram peletizadas a seco e o seu fornecimento, assim como da água, foi à vontade. Os coelhos foram pesados no início do experimento, com 36 dias de idade, aos 50 dias e no final do experimento, aos 70 dias de idade. As rações fornecidas e as sobras também foram pesadas a cada pesagem dos animais.

Os parâmetros de desempenho analisados foram o consumo de ração diário (CRD), ganho de peso diário (GPD), conversão alimentar (CA) nos períodos de 36 a 50 dias e 36 a 70 dias de idade e ao abate foram obtidos o peso de carcaça (PC) e rendimento de carcaça (RC). As características avaliadas referentes à carcaça foram obtidas com a carcaça quente, sem a cabeça.

Os dados de desempenho e de carcaça foram submetidos à análise de variância, utilizando-se o programa SAEG (1997), segundo o modelo:

$Y_{\mathrm{jk}}=\mathrm{m}+\mathrm{b}_{1} \mathrm{~N}_{\mathrm{j}}+\mathrm{b}_{2} \mathrm{~N}_{\mathrm{j}}^{2}+\mathrm{e}_{\mathrm{jk}}$, em que:

$\mathrm{Y}_{\mathrm{jk}}=$ valor observado das variáveis estudadas, relativa ao indivíduo $k$, que recebeu a ração com nível “ $j$ ” de inclusão de SGUM em substituição ao milho seco;

$\mathrm{m}=$ média geral de cada característica;

$\mathrm{b}_{1}=$ coeficiente linear de regressão da variável $\mathrm{Y}$, em função dos níveis de inclusão “ $j$ ” do SGUM às rações, 
para todo j maior que 1 ;

$\mathrm{b}_{2}=$ coeficiente quadrático de regressão da variável $\mathrm{Y}$, em função dos níveis de inclusão " $j$ ” do SGUM às rações, para todo j maior que 1 ;

$\mathrm{N}_{\mathrm{j}}=$ efeito do nível $j$ de inclusão do SGUM, sendo $=1$, $2,3,4$ e 5 e $j 1=$ ração com $0 \%$ de SGUM, $j 2=$ ração com $25 \%$ de SGUM em substituição ao milho seco, $j 3=$ ração com 50\% de SGUM em substituição ao milho seco, j4= ração com $75 \%$ de SGUM em substituição ao milho seco e $j 5=$ ração com $100 \%$ de SGUM em substituição ao milho seco;

$\mathrm{e}_{\mathrm{jk}}=$ erro aleatório associado a cada observação.

Para comparação das médias das características avaliadas, obtidas com os animais alimentados com a dieta referência em relação aos resultados obtidos com cada uma das demais dietas experimentais, foi utilizado o teste de Dunnett a 5\%.

\section{RESULTADOS E DISCUSSÃO}

Os valores de MS, PB, FDN, FDA, amido e EB da SGUM, com base na matéria natural, foram de 67,$04 ; 5,34 ; 4,76 ; 2,65 ; 47,29 \%$ e $2999 \mathrm{kcal} \mathrm{kg}^{-1}$, respectivamente. Os valores dos coeficientes de digestibilidade aparente da MS, PB, FDN e FDA foram maiores para a ração teste $(\mathrm{P}<0,05)$ que os obtidos para a ração referência (Tabela 2). Esses resultados demonstram que a inclusão da SGUM na dieta teve efeito positivo sobre a utilização digestiva dos nutrientes para coelhos, devido à fermentação dos grãos úmidos durante o processo de ensilagem.

Os coeficientes de digestibilidade aparente da MS, EB, PB, FDN, FDA e amido da SGUM são apresentados na tabela 3 , na qual são comparados com os valores de digestibilidade do milho seco, obtidos por diferentes autores. Os coeficientes de digestibilidade da MO e PB foram superiores para a SGUM em relação ao milho seco, mostrando que a fermentação que ocorre durante o processo de ensilagem realmente melhora a disponibilidade dos nutrientes. Para os coeficientes de digestibilidade dos demais nutrientes, os valores foram muito semelhantes, provavelmente devido ao fenômeno da cecotrofia, a qual permite maior utilização dos nutrientes pelos coelhos. SCAPINELLO et al. (1995) e VILLAMIDE et al. (1998), quando avaliaram grãos de milho seco para coelhos, também observaram valores inferiores de utilização digestiva dos nutrientes em relação aos do presente trabalho. Isso indica que o processo de ensilagem dos grãos de milho melhora a digestibilidade dos nutrientes desta importante matéria-prima utilizada em dietas para coelhos.

OLIVEIRA et al. (2004), avaliando a SGUM com suínos na fase de creche, obtiveram coeficientes de digestibilidade para matéria seca, proteína bruta, energia bruta e amido de, respectivamente, 80,92; 87,82; 90,91 e $100,00 \%$. O autor relata que o bom valor nutricional da SGUM pode ser explicado, em parte, pelo menor valor de $\mathrm{pH}(3,8)$, já que os ácidos ou álcalis diluídos podem promover gelatinização do amido sem necessitar de altas temperaturas. $\mathrm{O}$ valor de $\mathrm{pH}(3,9)$ encontrado na silagem utilizada no presente trabalho foi muito próximo ao encontrado por OLIVEIRA et al. (2004), mostrando ser um fator determinante para um bom valor nutricional do produto. Também LOPES (2000) afirma que ácidos orgânicos produzidos durante o processo fermentativo da silagem parecem ser responsáveis por causar rupturas na matriz proteica que recobre os grânulos de amido, bem como na estrutura desses grânulos com perda da estrutura cristalina, favorecendo a digestão e absorção do amido.

SANTOS et al. (2002), trabalhando com equinos, obtiveram coeficientes de digestibilidade para MS, PB, energia, amido, FDN e FDA da silagem de grão úmido de 86,$7 ; 64,2 ; 82,0 ; 100,0 ; 50,1$ e $32,3 \%$, respectivamente. A melhor eficiência de utilização da maioria dos nutrientes para coelhos em relação aos equinos deve-se, possivelmente, ao hábito da cecotrofia presente na espécie cunícula.

Tabela 2 - Coeficientes de digestibilidade da matéria seca, proteína bruta, fibra em detergente neutro (FDN), fibra em detergente ácido (FDA) e energia bruta das dietas referência e teste.

\begin{tabular}{|c|c|c|c|c|c|}
\hline \multirow{2}{*}{ Nutrientes } & \multicolumn{5}{|c|}{-----Coeficiente de Digestibilidade (\%)---- } \\
\hline & Dieta Referência & Dieta Teste & Média & $\mathrm{P}$ & $\mathrm{CV}(\%)$ \\
\hline Matéria seca & 68,4 & 75,5 & 71,9 & 0,028 & 10,8 \\
\hline Proteína bruta & 60,5 & 77,1 & 68,8 & 0,022 & 13,7 \\
\hline FDN & 30,8 & 37,9 & 34,4 & 0,040 & 23,5 \\
\hline FDA & 47,4 & 61,4 & 54,4 & 0,035 & 24,8 \\
\hline Energia bruta & 72,2 & 72,5 & 72,4 & 0,252 & 3,6 \\
\hline
\end{tabular}

Médias diferem entre si pelo Teste $\mathrm{F}$ quando $\mathrm{P}<0,05$. 
Tabela 3 - Coeficientes de digestibilidade da matéria seca, proteína bruta, energia bruta, fibra em detergente neutro (FDN), fibra em detergente ácido (FDA) e amido da SGUM e do milho seco para coelhos em crescimento.

\begin{tabular}{lcl}
\hline Nutrientes & - & - \\
& SGUM & \multicolumn{1}{c}{ Milho seco } \\
\hline Matéria seca & 94,50 & 84,69 (SCAPINELLO et al., 1995) \\
Energia bruta & 88,70 & 90,24 (FURLAN et al., 2003) \\
Proteína bruta & 99,70 & 87,70 (SCAPINELLO et al., 1991) \\
FDN & 95,00 & - \\
FDA & 66,10 & - \\
Amido & 97,40 & 95,56 (OTUTUMI et al., 2005) \\
\hline
\end{tabular}

Com base nos resultados dos coeficientes de digestibilidade aparente e a composição química da SGUM, os teores de MSD, PD, FDND, FDAD, Amido digestível e ED com base na matéria seca total foram de $94,42 \% ; 7,94 \% ; 6,74 \% ; 2,61 \% ; 68,73 \%$ e $3.973 \mathrm{kcal} \mathrm{kg}^{-1}$, respectivamente.

Observando-se a tabela 4, não foram observadas diferenças $(\mathrm{P}>0,05)$ tanto no desempenho quanto no peso e rendimento de carcaça entre os tratamentos, indicando que a SGUM apresenta-se como uma opção viável de utilização nas dietas para coelhos. Resultados semelhantes de ganho de peso diário, para a fase dos 32 aos 50 dias de idade, e rendimento de carcaça dos coelhos foram obtidos por CATELAN (2010), trabalhando com grãos ensilados de milheto até a substituição completa do milho da dieta. $\mathrm{Na}$ ensilagem, o maior teor de umidade do grão, em relação ao grão seco, favorece a fermentação no interior do silo, resultando em maior solubilização dos nutrientes e em aumento da susceptibilidade do amido à hidrólise enzimática, causando melhora na eficiência alimentar dos animais (GILL et al., 1982; SIMAS, 1997).

LOPES et al. (1999), trabalhando com suínos em crescimento-terminação, concluíram que a utilização de SGUM melhorou o ganho de peso e a conversão alimentar. No entanto, para SARTORI et al. (2002), a SGUM em substituição total ao milho seco não alterou o desempenho, o rendimento de carcaça e o peso de órgãos de frangos de corte criados até 21 dias de idade, concordando com os resultados encontrados no presente trabalho.

\section{CONCLUSÃO}

De acordo com as condições em que o experimento foi realizado, conclui-se que teores de MSD, PD, FDND, FDAD, Amido digestível e ED com base na matéria seca total foram, respectivamente, de $94,42 \% ; 7,94 \% ; 6,74 \% ; 2,61 \% ; 68,73 \%$ e $3973 \mathrm{kcal} \mathrm{kg}^{-1}$.

Tabela 4 - Peso vivo aos 50 e 70 dias de idade (PV50, PV70), ganho de peso diário (GPD), consumo de ração diário (CRD), conversão alimentar (CA) nos período de 36 a 50 e 36 a 70 dias de idade, peso de carcaça (PC) e rendimento de carcaça (RC) de coelhos de acordo com os níveis de substituição do milho seco pela silagem de grãos úmidos de milho (SGUM).

\begin{tabular}{|c|c|c|c|c|c|c|c|}
\hline \multirow{2}{*}{ Características } & \multicolumn{5}{|c|}{-----------Níveis de substituição do milho pela SGUM (\%)------------ } & \multirow[b]{2}{*}{ Média } & \multirow[b]{2}{*}{$\mathrm{CV}(\%)$} \\
\hline & Teste & 25 & 50 & 75 & 100 & & \\
\hline \multicolumn{8}{|c|}{50 dias de idade } \\
\hline PV50 (g) & 1590 & 1623 & 1546 & 1572 & 1543 & 1575 & 5,22 \\
\hline GPD $(g)$ & 41,4 & 44,0 & 38,1 & 40,0 & 37,8 & 40,3 & 15,72 \\
\hline CRD (g) & 121 & 124 & 117 & 117 & 117 & 119 & 9,97 \\
\hline CA & 2,94 & 2,88 & 3,16 & 3,00 & 3,14 & 3,03 & 14,2 \\
\hline \multicolumn{8}{|c|}{70} \\
\hline PV70 (g) & 2055 & 2043 & 1993 & 2071 & 1952 & 2023 & 7,64 \\
\hline GPD (g) & 30,43 & 30,06 & 28,55 & 30,89 & 27,31 & 29,45 & 15,91 \\
\hline CRD (g) & 120 & 120 & 123 & 127 & 126 & 123 & 12,21 \\
\hline CA & 4,0 & 4,0 & 4,3 & 4,2 & 4,6 & 4,3 & 16,28 \\
\hline $\mathrm{PC}(\mathrm{g})$ & 1087 & 1046 & 1076 & 1107 & 1040 & 1071 & 9,28 \\
\hline $\mathrm{RC}(\%)$ & 52,81 & 51,24 & 54,07 & 53,51 & 53,25 & 52,98 & 5,66 \\
\hline
\end{tabular}

Ciência Rural, v.41, n.3, mar, 2011. 
A silagem de grão úmido de milho pode substituir o grão de milho seco em dietas para coelhos, sendo uma alternativa para a utilização de grão na propriedade, diminuindo assim os custos de armazenamento.

\section{REFERÊNCIAS}

AEC. Recomendações para nutrição. 5.ed. Rhône Poulenc, $1987.86 \mathrm{p}$.

BIAGI, J.D. et al. Importância da qualidade dos grãos na alimentação animal. In: SIMPOSIO LATINO AMERICANO DE NUTRIÇÃO ANIMAL; SEMINÁRIO SOBRE A TECNOLOGIA DE PRODUÇÃO DE RAÇÕES. Anais... Campinas: CBNA, 1996. p.21-45.

BLAS, E.; GIDENNE, T. Digestion of starch and sugars. In: DE BLAS, C.; WEISEMAN, J. (Ed.). The nutrition of rabbit. Wallingford: CABI Publishing, 1998. p.17-38.

GILL, D.R. et al. Corn moisture and processing for finishing steers. Journal of Animal Science, v.55, supl.1, p.423, 1982.

CATELAN, F. Avaliação de grãos de milheto (Pennisetum glaucum) na alimentação de coelhos em crescimento. 2010. 52f. Tese (Doutorado em Zootecnia) - Universidade Estadual de Maringá, PR.

FURLAN, A.C. et al. Valor nutritivo e desempenho de coelhos em crescimento alimentados com rações contendo milho extrusado. Revista Brasileira de Zootecnia, v.32, n.5, p.1157-1165, 2003. Disponível em: <http://www.scielo.br/scielo.php?pid=S1516$35982003000500016 \&$ script $=$ sci_abstract\&tlng $=\mathrm{pt}>$. Acesso em: 28 nov. 2010 . doi: 10.1590/S1516-35982003000500016.

JOBIM, C.C. et al. Produção e utilização de grãos de cereais. In: SIMPÓSIO DE FORRAGICULTURA E PASTAGENS, 2., 2001, Lavras, MG. Anais... Lavras: UFLA, 2001. p.277-310.

LIMA, G.J.M.M. et al. Determinação da composição química e do valor energético de silagem de grãos úmidos de milho para suínos. In: CONGRSSO NACIONAL DE MILHO E SORGO, 22., 1998, Recife. Anais... Recife: ABMS, [1998]. 2par. CDROM. Seção Industrialização e Tecnologia de Alimentos.

LOPES, A.B.R.C. et al. Silagem de grãos úmidos de milho para suínos na fase inicial. In: REUNIÃO ANUAL DA SOCIEDADE BRASILEIRA DE ZOOTECNIA, 36., 1999, Porto Alegre, RS. Anais... São Paulo: Gnosis, [1999]. 17par. CD-ROM - Nutrição de Não-Ruminantes. NUN-112.

LOPES, R.P. et al. Energia no pré-processamento de produtos agrícolas. In: LOPES, R.P. et al. Secagem e armazenamento de produtos agrícolas. Viçosa: UFV, 2000. 1 CDROM.

LOPES, A.B.R.C. et al. Efeito do processo de ensilagem de grãos úmidos de milho nas características microscópicas do amido. Brazilian Journal of Food Technology, v.5, n.96, p.177-181, 2002. Disponível em: <http://www.ital.sp.gov.br/ bj/artigos/bjft/2002/p0296.pdf>. Acesso em: 15 abr. 2010.

MATTERSON, L.D. et al. The metabolizable energy of feed ingredients for chickens. Research Report, v.7, n.1, p.1114,1965 .

OLIVEIRA, R.P. et al. Valor nutritivo e desempenho de leitões alimentados com rações contendo silagem de grãos úmidos de milho. Revista Brasileira de Zootecnia, v.33, n.1, p.146156, 2004. Disponível em: <http://www.scielo.br/pdf/rbz/v33n1/ a19v33n1.pdf>. Acesso em: 19 abr. 2010.

OTUTUMI, L.K. et al. Digestibilidade e atividade enzimática intestinal de coelhos em crescimento alimentados com diferentes fontes de amido processadas ou não por extrusão. Revista Brasileira de Zootecnia, v.34, n.2, p.557-567, 2005. Disponível em: <http:// www.scielo.br/scielo.php? script $=$ sci $\operatorname{arttext} \& \mathrm{pid}=\mathrm{S} 1516$ 35982005000200025>. Acesso em: 28 nov. 2010. doi: 10.1590/ S1516-35982005000200025.

PEREIRA, J.R.A.; ROSSI, J.R.P. Manual prático para avaliação nutricional dos alimentos. Piracicaba: FEALQ, 1995. 25p.

PEREZ, J.M. et al. European reference method for in vivo determination of diet digestibility in rabbits. World Rabbit Science, v.3, n.1, p.41-43, 1995. Disponível em: <http:// www.wrs.upv.es/files/guides/egran_in_vivo1995.pdf>. Acesso em: 15 abr. 2010.

PHILLIP, L.E.; FELLNER, V. Effects of bacterial inoculation of high moisture ear corn on its aerobic stability, digestion and utilization for growth by beef steers. Journal of Animal Science, v.70, p.3178-3187, 1992. Disponível em: <http:// jas.fass.org/cgi/reprint/70/10/3178.pdf $>$. Acesso em: 9 abr. 2010. PMID: 1429293.

POORE, J.R. et al. Total starch and relative starch availability of grains. In: BIENNIAL CONFERENCE ON RUMEN FUNCTION, 20., 1989, Chicago. Abstracts... Chicago, 1989. p.35.

SANTOS, C.P. et al. Avaliação da silagem de grãos úmidos de milho na alimentação de equinos em crescimento: valor nutricional e desempenho. Revista Brasileira de Zootecnia, v.31, n.3, p.1214-1222, 2002. Disponível em: <http://www.scielo.br/pdf/ rbz/v31n3/13073.pdf>. Acesso em: 28 mar. 2010.

SARTORI, J.R. et al. Silagem de grãos úmidos de milho na alimentação de frangos de corte. Pesquisa Agropecuária Brasileira, v.37, p.1009-1015, 2002. Disponível em: <http:/ /www.scielo.br/pdf/pab/v37n7/10805.pdf >. Acesso em: 11 abr. 2010. doi: 10.1590/S0100-204X2002000700015.

SCAPINELLO, C. et al. In: REUNIÃO ANUAL DA SOCIEDADE BRASILEIRA DE ZOOTECNIA, 28., 1991, João Pessoa, PB. Anais... João Pessoa: SBZ, 1991. p.355.

SCAPINELLO, C. et al. Valor nutritivo do milho, do farelo de soja e do feno de aveia para coelhos em crescimento. Revista Brasileira de Zootecnia, v.24, n.6, p.1001-1007, 1995. Disponível em: <http://www.revistasbz.org.br/scripts/revista/ sbz1/Resumo.asp?NumArtigo=409>. Acesso em: 20 mar. 2010.

SILVA, D.J. Análise de alimentos (métodos químicos e biológicos). 2.ed. Viçosa: UFV, 1990. 165p.

SIMAS, J.M. Processamento de grãos para rações de vacas leiteiras. In: SIMPÓSIO SOBRE PRODUÇÃO ANIMAL, 9., 1997, Piracicaba, SP. Anais... Piracicaba: Fundação de Estudos Agrários Luiz de Queiroz, 1997. p.23-34.

UNIVERSIDADE FEDERAL DE VIÇOSA- UFV. SAEG. Sistema de análises estatísticas e genéticas. Versão 7.1. Viçosa, MG, 1997. 150p. (Manual do usuário).

VILLAMIDE, M.J. et al. Feed evolution. In: DE BLAS, C.; WEISEMAN, J. (Eds). The nutrition of rabbit. Wallingford, Inglaterra: CABI Publishing, 1998. p.89-101. 